\title{
The impact of forest logging and fragmentation on carnivore species composition, density and occupancy in Madagascar"s rainforests
}

\author{
Brian D. Gerber, Sarah M. Karpanty and Johny Randrianantenaina
}

\begin{abstract}
Forest carnivores are threatened globally by logging and forest fragmentation yet we know relatively little about how such change affects predator populations. This is especially true in Madagascar, where carnivores have not been extensively studied. To understand better the effects of logging and fragmentation on Malagasy carnivores we evaluated species composition, density of fossa Cryptoprocta ferox and Malagasy civet Fossa fossana, and carnivore occupancy in central-eastern Madagascar. We photographically-sampled carnivores in two contiguous (primary and selectively-logged) and two fragmented rainforests (fragments $<2.5$ and $>_{15} \mathrm{~km}$ from intact forest). Species composition varied, with more native carnivores in the contiguous than fragmented rainforests. F. fossana was absent from fragmented rainforests and at a lower density in selectively-logged than in primary rainforest (mean $1.38 \pm$ SE 0.22 and $3.19 \pm$ SE 0.55 individuals $\mathrm{km}^{-2}$, respectively). C. ferox was detected in fragments $<2.5 \mathrm{~km}$ from forest and had similar densities in primary and selectivelylogged forests $(0.12 \pm \mathrm{SE} \quad 0.05$ and $0.09 \pm \mathrm{SE} \quad 0.04$ adults $\mathrm{km}^{-2}$, respectively) but was absent in fragments $>15 \mathrm{~km}$ from forest. We identified only two protected areas in Madagascar that may maintain $>300$ adult C. ferox. Occupancy of broad-striped mongoose Galidictis fasciata was positively related to fragment size whereas occupancy of ring-tailed mongoose Galidia elegans elegans was negatively associated with increasing exotic wild cat (Felis spp.) activity at a camera site. Degraded rainforest fragments are difficult environments for Malagasy carnivores to occupy; there is a need to prioritize the reconnection and maintenance of contiguous forest tracts.
\end{abstract}

Keywords Cryptoprocta ferox, Eupleridae, fossa, Madagascar, Malagasy civet, mongoose

This paper contains supplementary material that can be found online at http://journals.cambridge.org

Brian D. Gerber* (Corresponding author) and SARAH M. Karpanty Department of Fish and Wildlife Conservation, Virginia Tech, Blacksburg, Virginia, USA. E-mail bgerber@colostate.edu

JoHny RandRianantenaina Centre ValBio, Ranomafana, Madagascar

* Current address: 201 Wagar, Department of Fish, Wildlife \& Conservation Biology, Colorado State University, Fort Collins, Colorado 80523-1474, USA

Received 21 February 2011. Revision requested 16 May 2011.

Accepted 1 June 2011.

\section{Introduction}

Carnivores are one of the most threatened groups of $\checkmark$ terrestrial mammals (Karanth \& Chellam, 2009). Declines of predators are often attributed to habitat loss and fragmentation but few quantitative studies have examined how carnivore populations and communities change with habitat loss or fragmentation (Crooks, 2002; Michalski \& Peres, 2005). This is particularly true for Madagascar's carnivores, with knowledge lacking about their ecology and the effects of anthropogenic disturbances (Irwin et al., 2010), especially in the eastern rainforest where only short-term studies have been conducted (Gerber et al., 2010). With only $16 \%$ of the original primary forests extant in Madagascar and those remaining becoming smaller and more isolated over time (Harper et al., 2007), habitat loss and fragmentation are serious threats to many endemic species (Irwin et al., 2010).

To conserve Madagascar's unique biodiversity science is being used to prioritize areas for conservation and restoration. This planning requires reliable knowledge of species' distributions and the effects of human disturbance. Although studies of many Malagasy taxa have directly benefited conservation planning the dearth of studies on carnivores has excluded them from consideration (Kremen et al., 2008). Given that carnivores often have the largest area requirements of all fauna, can affect ecosystem dynamics (Roemer et al., 2009), and serve as useful focal species for planning (Carroll et al., 2001), a better understanding of the ecology of Malagasy carnivores is required.

Of the 10 extant carnivore species in the endemic family Eupleridae (Yoder et al., 2003; Durbin et al., 2010; Goodman \& Helgen, 2010), five are known to occupy the centraleastern rainforests (broad-striped mongoose Galidictis fasciata, fossa Cryptoprocta ferox, Malagasy civet Fossa fossana, ring-tailed mongoose Galidia elegans elegans and small-toothed civet Eupleres goudotii; Gerber et al., 2010). Of these five carnivores, all but $G$. e. elegans are thought to be declining (IUCN, 2011). C. ferox and G. e. elegans are of particular interest as both are known to prey on lemurs (Goodman, 2003), many of which are also threatened (IUCN, 2011).

Our objectives were to (1) quantify carnivore species composition, density, and occupancy across a continuum of disturbed rainforests to gain insights into the impacts of forest logging and fragmentation on Malagasy carnivores, (2) investigate the influence of exotic carnivore species, 


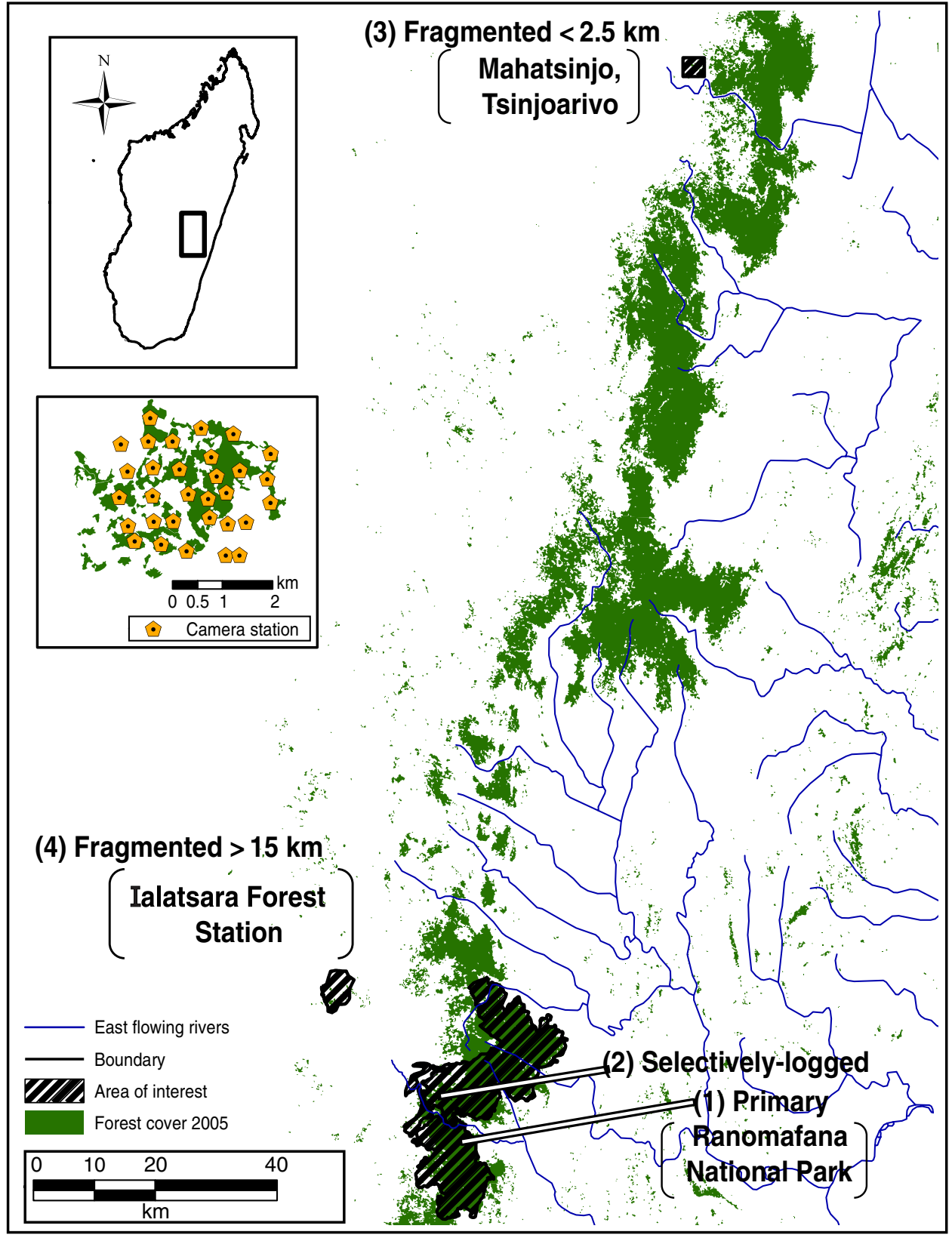

FIG. 1 The four rainforest study sites where we sampled carnivores using a grid of camera traps during May-October 2008 (Areas 1 \& 2) and October-December, 2009 (Areas 3 \& 4). Top inset shows the location of the main map in Madagascar, and the bottom the layout of camera stations among rainforest fragments at Mahatsinjo, Tsinjoarivo (Area 3), as an example. human activity, landscape characteristics and microhabitat on the occupancy of native carnivores, and (3) estimate the population of C. ferox island-wide as it is of particular interest to conservation planners because of its ecological role as the largest carnivore on Madagascar. This is the first published study of the effects of habitat disturbance on the carnivore community of the Malagasy rainforests.

\section{Study area}

We carried out this research in four areas along Madagascar's eastern rainforest escarpment, selected to represent a continuum of exposure to forest logging and fragmentation (Fig. 1). We sampled in contiguous rainforest at the Valohoaka-Vatoharanana (Area 1, primary) and Sahamalaotra (2, selectively-logged) trail systems in Ranomafana National Park, which protects $412 \mathrm{~km}^{2}$ of mostly mid altitude rainforest; these two areas are separated by a river that divides the Park into two main parcels. The primary rainforest comprises a mixture of unlogged forest with little human disturbance and forest with minimal selective logging; the selectively-logged rainforest experienced moderate logging pre-1991 (J.C. Razafimahaimodison, pers. comm.). We sampled in two fragmented rainforests, at Mahatsinjo,Tsinjoarivo (3, fragments $<2.5 \mathrm{~km}$ from intact forest) and Ialatsara Forest Station (4, fragments $>15 \mathrm{~km}$ from intact forest).

We consider forest fragmentation to include the additive or synergistic effects of forest loss, fragmentation and 
TABLE 1 Details of the camera-trap sampling grids at four rainforest sites in eastern Madagascar (primary, selectively-logged, fragments $<2.5 \mathrm{~km}$ and $>15 \mathrm{~km}$ from intact forest; numbered in Fig. 1), with summary capture-recapture data of the individually-identifiable Cryptoprocta ferox and Fossa fossana, and number of camera-trap events of other carnivore species.

\begin{tabular}{|c|c|c|c|c|}
\hline & 1, Primary & 2, Selectively-logged & 3 , Fragments $<2.5 \mathrm{~km}$ & 4 , Fragments $>15 \mathrm{~km}$ \\
\hline $\begin{array}{l}\text { Mean camera station spacing } \pm S D \text {, } \\
m \text { (no. of stations) }\end{array}$ & $513 \pm 93(27)$ & $567 \pm 94(26)$ & $558 \pm 128(31)$ & $584 \pm 86(27)$ \\
\hline Sampling dates & $\begin{array}{l}12 \text { Aug. } 2008- \\
9 \text { Oct. } 2008\end{array}$ & $\begin{array}{l}9 \text { Jun. } 2008- \\
9 \text { Aug. } 2008\end{array}$ & $\begin{array}{l}15 \text { Oct. } 2009- \\
7 \text { Dec. } 2009\end{array}$ & $\begin{array}{r}20 \text { Oct. } 2008- \\
11 \text { Dec. } 2008\end{array}$ \\
\hline No. of trap nights ${ }^{1}$ & 1,446 & 1,417 & 1,379 & 1,323 \\
\hline \multicolumn{5}{|l|}{ No. of individually-identifiable species } \\
\hline $\begin{array}{l}\text { Cryptoprocta ferox (adults): male-female } \\
\text { (recaptures) }^{2}\end{array}$ & $3-3(75)$ & $2-2(37)$ & $1-0(1)$ & $0-0(0)$ \\
\hline Fossa fossana: male-female (recaptures) ${ }^{2}$ & $16-17(644)$ & $11-11(428)$ & $0-0(0)$ & $0-0(0)$ \\
\hline \multicolumn{5}{|c|}{ No. of trap events of individually-unidentifiable species ${ }^{3}$} \\
\hline Canis familiaris & 7 & 17 & 169 & 97 \\
\hline Eupleres goudotii & 2 & 16 & 0 & 0 \\
\hline Felis spp. & 0 & 0 & 23 & 16 \\
\hline Galidia elegans elegans & 1,554 & 427 & 28 & 185 \\
\hline Galidictis fasciata & 52 & 10 & 10 & 27 \\
\hline Viverricula indica & 0 & 0 & 22 & 49 \\
\hline
\end{tabular}

${ }^{1}$ Trap nights are total sampling effort where at least one of two remote cameras was functioning at a station for 1 day

${ }^{2}$ Individuals can be re-caught at multiple stations on a single sampling occasion

${ }^{3}$ Number of photographic events (lumping all photos of a species within 30 minutes as one event) of a species at a site

degradation as such disturbances are often concurrent and we cannot distinguish each effect in this study (Laurance \& Cochrane, 2001). The two distances were selected to assess if proximity to contiguous forest, and a hypothesized proximity to more intact carnivore populations, affects our findings. Area 3 is $150 \mathrm{~km}$ north of Ranomafana National Park within a network of unprotected rainforest fragments that from its closest edge is $<2.5 \mathrm{~km}$ from the large tract of contiguous primary rainforest (Fig. 1); this area comprises 19 fragments each of $<_{7}$ ha, eight fragments of $10-40$ ha and one fragment of 192 ha, as determined by combining GPS mapping in December 2009 with IKONOS 2001 satellite imagery. The matrix surrounding these fragments is dominated by agriculture and naturally regenerating shrub. Area 4 is in a protected, fragmented rainforest separated by $>15 \mathrm{~km}$ from the main tract of contiguous primary rainforest by a humandominated landscape (Fig. 1); this area comprises four fragments of 2-5 ha, five fragments 10-64 ha, and one fragment of 240 ha, as determined by GPS-based mapping in November 2008. These fragments are surrounded by a matrix of shrub, open-burned, exotic pine and eucalyptus, and minimal agriculture.

Local people used both fragmented sites for travel and forest products but only lived between the forest fragments in the unprotected site 3 (where fragments are $<2.5 \mathrm{~km}$ from intact forest). In both fragmented areas forest edges are hard transitions to open habitat, caused by burning of forest for planting crops or grazing.

\section{Methods}

The two contiguous rainforests were sampled in the colddry season (May-October 2008) and the two fragmented rainforests in the warm-dry season (October-December 2009). The timing of sampling was logistically constrained and we therefore prioritized the sampling of similar forests in the same season. Although results between contiguous and fragmented forests were confounded with season we expected habitat differences between forest types were likely to have a larger effect than season. Specifically, we expected that differences in prey populations because of habitat differences would have a larger impact on the carnivore populations than seasonal variation. In Ranomafana National Park the 5-year mean (2005-2009) minimummaximum daily temperature was $13-19{ }^{\circ} \mathrm{C}$ and mean daily rainfall $6.4 \pm \mathrm{SD} 4.3 \mathrm{~mm}$ in the cold-dry season and $16-25^{\circ} \mathrm{C}$ and $7.4 \pm \mathrm{SD} 12.1 \mathrm{~mm}$ in the warm-dry season.

We used a random starting point to establish a systematic grid of camera stations, along established trail systems, to photographically sample carnivores in the four areas. Following recommendations for survey design (Karanth \& Nichols, 2002) and using the results from a preliminary study (Gerber et al., 2010), we deployed a minimum of 26 camera stations for at least 52 days in each grid (Table 1 ). Among all grids the mean spacing among adjacent stations was $555 \pm \mathrm{SD} 100 \mathrm{~m}$. Camera stations included two independently-operating passive infrared cameras mounted on opposite sides of a trail. Cameras were $20 \mathrm{~cm}$ 
above the ground and active continuously. Camera types were Deercam DC30o (DeerCam, Park Falls, USA) and Reconyx PC85 (Reconyx, Inc. Holmen, USA). We used chicken meat as a scent lure during the entire sampling period in the primary forest (Area 1) and in fragments $>15$ $\mathrm{km}$ from intact forest (4) but only used it for the second half of sampling in the selectively-logged forest (2) and in fragments $<2.5 \mathrm{~km}$ from intact forest (3). Partially sampling without lure allowed us to assess potential lure-induced biases on population estimates and to evaluate the effects of lure on detection probability. In a separate analysis, not presented here, we found no effect of this lure on the activity patterns of any of the carnivore species in the study area (Gerber, 2010) and no effect on F. fossana immigration into or emigration from the sampling grid, density estimation, or maximum movement distances (Gerber et al., 2011). We checked camera stations every 3-5 days to ensure continued operation.

We measured camera-, grid- and landscape-level habitat features. Camera-level vegetation was sampled along four transects radiating in each cardinal direction from camera stations. Along each transect we established sampling points at $0,25,50$ and $75 \mathrm{~m}$ from the camera station for a total of 13 vegetation sampling points per camera station. At each of the 13 points we recorded the diameter at breast height (at $\left.130 \mathrm{~cm}, \mathrm{D}_{130}\right)$, and the distance of the nearest tree $\left(\mathrm{D}_{130}\right.$ $\geqslant 10 \mathrm{~cm}$ ) in each quarter surrounding the centre point. At each point we also recorded presence or absence of vegetation cover every $2 \mathrm{~m}$ for a total of $10 \mathrm{~m}$ in each cardinal direction for 20 point intercepts, giving a total of 260 point intercepts per camera station. Point intercept vegetation cover measurements included percentage cover for down and dead trees $\left(\geqslant 15 \mathrm{~cm} \mathrm{D}_{130}\right)$, herbaceous ground plants (0-0.5 m height), woody-shrubs $(0.5-5 \mathrm{~m}, \leqslant 10 \mathrm{~cm}$ $\left.\mathrm{D}_{130}\right)$, low canopy trees $\left(0-5 \mathrm{~m}, \geqslant 10 \mathrm{~cm} \mathrm{D}_{130}\right)$, medium canopy trees $\left(5-15 \mathrm{~m}, \geqslant 10 \mathrm{~cm} \mathrm{D}_{130}\right)$, and high canopy trees $\left(\geqslant 15 \mathrm{~m}, \geqslant 10 \mathrm{~cm} \mathrm{D}_{130}\right)$. We used the nearest tree distances and $D_{130}$ to estimate tree density and basal area using an unbiased point-centered-quarter estimator (Pollard, 1971). To test for grid-level differences in vegetation characteristics we calculated the mean and standard error for each variable and used Welch's unequal variance ANOVA to test for differences among sites (Zar, 1998). When the global test indicated a difference among grids we used the DunnettTukey-Kramer pairwise multiple comparison test, adjusting for unequal variances and sample size (Dunnett, 1980).

We used ArcGIS v. 9.2 (ESRI, Redlands, USA) and FRAGSTATS (McGarigal et al., 2002) to measure landscapeand camera-level variables for each grid. We quantified the following landscape variables: rainforest fragment size (Area), nearest distance from camera stations to the matrix (DistMatrix), camera station distance to the nearest village (DistVillage), Euclidian distance from each fragment to nearest neighbouring fragment (ENN), and the fragment shape as a shape index (Shape). We also quantified camera station forest cover type as either rainforest or matrix (ForestType) and trail type as either maintained or secondary trail (Trail).

\section{Data analyses}

Among the four grids we compared the composition of native and exotic carnivore species. We used a binomial model, including capture frequency and sampling effort, to evaluate the number of trap nights needed to obtain a $95 \%$ probability of a single detection of native and exotic carnivores at each grid (Tobler et al., 2008). A trap night was defined as a 24-hour period during which at least one of the two cameras at a station was functioning.

We estimated density of $C$. ferox and F. fossana, as they are individually-identifiable (Gerber et al., 2010), using a maximum-likelihood spatially-explicit capture-recapture model in DENSITY v. 4.4 (Efford, 2009; Efford et al., 2009). We applied a habitat mask to remove villages, roads and agricultural land (non-habitat) from the area estimation. We compared the fit of three detection functions (halfnormal, hazard-rate and negative-exponential) to model detection probability variation away from an animal's home range centre. We fitted a detection model by maximizing the conditional likelihood in which the parameters $g_{o}$ (detection process when a single trap is located at the centre of an animal's home range) and $\sigma$ (spatial scale detection process away from the centre of the home range) were modelled using a priori biologically plausible models, including time (Time), the effect of lure (Lure) as a difference between the non-lure and lure sampling periods, behaviour effect (b; trap happy vs trap shy), individual heterogeneity $(\mathrm{H}$; Pledger's 2-point mixture), and males vs females (Sex). Model selection was evaluated using Akaike's Information Criterion with a small sample size bias correction $\left(\mathrm{AIC}_{\mathrm{c}}\right)$. We model-averaged parameter estimates to incorporate model selection uncertainty (Burnham \& Anderson, 2002). We defined a significant statistical difference between estimates when the $95 \%$ confidence intervals of two means overlapped by no more than half the mean margin of error (mean of the two radii of the confidence intervals being compared), equivalent to a conservative hypothesis test at $\alpha=0.05$ (Cumming \& Finch, 2005).

We used occupancy modelling to relate the probability of the presence of a species to habitat characteristics, incorporating the reality that species are often imperfectly detected (MacKenzie \& Nichols, 2004). We estimated site occupancy as the probability of use of a $75-\mathrm{m}$ radius surrounding the camera stations within each grid and then calculated the average occupancy, or proportion of camera stations used, of each grid, which we interpret as an index of abundance (MacKenzie \& Nichols, 2004). We assumed no changes in occupancy (i.e. geographical and demographic 
TABLE 2 Vegetation structure (mean $\pm \mathrm{SE}$ ) of four rainforest sites (primary, selectively-logged, fragments $<2.5 \mathrm{~km}$ and $>15 \mathrm{~km}$ from intact forest; numbered in Fig. 1), in order of increasing levels of disturbance, in eastern Madagascar. Different subscripted letters associated with variables across sites indicate sites that differed significantly in that variable (experiment-wise $\alpha=0.05$ ).

\begin{tabular}{lcccc}
\hline Vegetation structure & $\begin{array}{l}\text { 1, Primary } \\
(\mathrm{n}=27)\end{array}$ & $\begin{array}{l}\text { 2, Selectively-logged } \\
(\mathrm{n}=26)\end{array}$ & $\begin{array}{l}3 \text {, Fragments }<2.5 \mathrm{~km}^{*} \\
(\mathrm{n}=27)\end{array}$ & $\begin{array}{l}4, \text { Fragments }>15 \mathrm{~km}^{*} \\
(\mathrm{n}=13)\end{array}$ \\
\hline Tree density $\left(\geqslant 10 \mathrm{~cm} \mathrm{D}_{130}, \mathrm{stems} \mathrm{ha}^{-1}\right)$ & $1,612 \pm 27^{\mathrm{a}}$ & $622 \pm 17^{\mathrm{b}}$ & $337 \pm 11^{\mathrm{c}}$ & $500 \pm 11^{\mathrm{bc}}$ \\
Tree basal area $\left(\right.$ stems $\left.\geqslant 10 \mathrm{~cm} \mathrm{D}_{130}, \mathrm{~m}^{2} \mathrm{ha}^{-1}\right)$ & $102 \pm 13^{\mathrm{a}}$ & $24 \pm 2^{\mathrm{b}}$ & $8 \pm 4^{\mathrm{c}}$ & $13 \pm 3^{\mathrm{c}}$ \\
\% down/dead cover $\left(\geqslant 15 \mathrm{~cm} \mathrm{D}_{130}\right)$ & $5 \pm 2^{\mathrm{a}}$ & $4 \pm 0.5^{\mathrm{a}}$ & $2 \pm 0.3^{\mathrm{b}}$ & $0.6 \pm 0.6^{\mathrm{c}}$ \\
\% ground cover $(0-0.5 \mathrm{~m})$ & $70 \pm 4^{\mathrm{a}}$ & $91 \pm 1^{\mathrm{b}}$ & $57 \pm 4^{\mathrm{a}}$ & $91 \pm 3^{\mathrm{b}}$ \\
\% shrub cover $(0.5-5 \mathrm{~m})$ & $87 \pm 4^{\mathrm{ab}}$ & $94 \pm 2^{\mathrm{a}}$ & $78 \pm 4^{\mathrm{b}}$ & $85 \pm 3^{\mathrm{b}}$ \\
\% low tree canopy cover $(0-5 \mathrm{~m})$ & $5 \pm 2^{\mathrm{a}}$ & $11 \pm 0.9^{\mathrm{b}}$ & $45 \pm 4^{\mathrm{c}}$ & $16 \pm 2^{\mathrm{b}}$ \\
\% mid tree canopy cover $(5-15 \mathrm{~m})$ & $58 \pm 5^{\mathrm{a}}$ & $86 \pm 2^{\mathrm{b}}$ & $27 \pm 4^{\mathrm{c}}$ & $31 \pm 4^{\mathrm{c}}$ \\
\% high tree canopy cover $(\geqslant 15 \mathrm{~m})$ & $66 \pm 4^{\mathrm{a}}$ & $38 \pm 4^{\mathrm{b}}$ & $6 \pm 2^{\mathrm{c}}$ & $4 \pm 2^{\mathrm{c}}$ \\
\hline
\end{tabular}

${ }^{*}$ Only includes the vegetation structure of the forested areas, not of the matrix around them

closure) while sampling and applied a single-season occupancy model, available in PRESENCE v. 3.0 (Hines, 2006). We analysed each species by grouping data from the two contiguous rainforest grids (primary and selectivelylogged) and grouping separately the two fragmented rainforest grids (fragments $<2.5$ and $>15 \mathrm{~km}$ ), as each group was sampled within the same season and vegetation structure was more similar within a group.

We included covariates for the probability of both occupancy and detection to evaluate biologically-driven hypotheses. Covariates included camera- grid- and landscape-level vegetation and canopy cover variables as described above, as well as the effect of lure as a survey covariate and a difference between grouped grids (Grid). Additionally, we evaluated the trap success for exotic carnivores and people at camera stations as a measure of disturbance that could influence occupancy. Trap success was calculated as the frequency of capture events by species at a station per 100 trap nights. To avoid multicollinearity we examined correlations among variables and did not include variables with $r>0.6$ in the same model. We evaluated global model fit by assessing the degree of overdispersion $(\hat{c})$ using a goodness-of-fit test with 10,000 bootstraps and adjusted $\hat{c}$ if $\chi^{2}$ tests indicated lack of fit $(\mathrm{P}<0.05$; MacKenzie \& Bailey, 2004). We evaluated competing models using $\mathrm{AIC}_{\mathrm{c}}$ as described for the density analyses above.

To consider the potential population of $C$. ferox across all of Madagascar we developed a basic population model that incorporated our current knowledge of available habitat, protected area coverage, and known densities and effects of forest fragmentation. We used this model to estimate the island-wide population of C. ferox, the number of distinct populations, and the connectedness of those populations by extrapolating this study's rainforest adult-only density estimates and an adult-only, dry forest estimate (o.18 adults $\mathrm{km}^{-2}$; Hawkins \& Racey, 2005).

We used ArcGIS to quantify available primary forest in 2005 (Conservation International, 2010) and the extent of current protected areas (Kremen et al., 2008). We assumed C. ferox is forest-dependent and classified Madagascar's forests into zones of eastern rainforest, western dry forest and southern spiny forest (Harper et al., 2007). We excluded the spiny forests from population estimates as there are no C. ferox density estimates from that region and we felt that other densities would be inappropriate as a proxy, given the major differences in vegetation and prey. In the rainforest and dry forest, we firstly identified forest fragments that could contain a single adult C. ferox (based on density estimates) and estimated population size of each fragment. Secondly, we arbitrarily removed fragments $<25$ ha to eliminate highly fragmented areas. Finally, we spatiallyjoined all remaining fragments $\leqslant 4.9 \mathrm{~km}$ from each other as a single population of a forest complex, as movements of C. ferox in the human-dominated landscape are probably constrained to this distance (Kotschwar, 2010).

\section{Results}

Grid-level vegetation structure differed greatly among all forests but was most similar between fragmented forests (Table 2). We found the highest tree density and basal area in the primary forest, followed by the selectively-logged, and then the fragmented forests. High canopy cover was greatest in the primary forest, and the selectively-logged forest had the greatest mid canopy cover. The percentage of low canopy cover was small at all forests, except for the fragments $<2.5 \mathrm{~km}$ from intact forest, which had 10 times the percentage of low canopy cover compared to the primary forest. We observed $>78 \%$ shrub canopy cover in all forests.

We detected all known endemic central-eastern rainforest carnivores in the primary and selectively-logged contiguous rainforests. We found reduced numbers of endemic carnivore species in the fragmented rainforests, with $G$. fasciata and $G$. e. elegans detected in both fragmented forests, F. fossana and E. goudotii absent from 
TABLE 3 Model-averaged grid occupancy $( \pm S E)$ of native and exotic carnivores in two contiguous rainforest sites and in the forest and matrix of two fragmented (fragments $<2.5 \mathrm{~km}$ and $>15 \mathrm{~km}$ from intact forest) sites (Fig. 1). The values can be interpreted as the proportion of camera stations used per grid and thus an index of abundance for comparisons between sites.

\begin{tabular}{|c|c|c|c|c|c|c|}
\hline \multirow[b]{3}{*}{ Species } & & & \multicolumn{4}{|c|}{ Fragmented rainforest } \\
\hline & \multicolumn{2}{|c|}{ Contiguous rainforest } & \multicolumn{2}{|c|}{$3,<2.5 \mathrm{~km}$ from primary forest } & \multicolumn{2}{|c|}{$4,>15 \mathrm{~km}$ from primary forest } \\
\hline & 1, Primary & 2, Selectively-logged & Rainforest & Matrix & Rainforest & Matrix \\
\hline C. familiaris & $0.27 \pm 0.08$ & $0.39 \pm 0.10$ & $0.87 \pm 0.07$ & $0.87 \pm 0.07$ & $0.67 \pm 0.06$ & $0.67 \pm 0.06$ \\
\hline C. ferox & $0.93 \pm 0.05$ & $0.72 \pm 0.08$ & $0.069^{*}$ & 0.00 & 0.00 & 0.00 \\
\hline E. goudotii & $0.07^{\star}$ & $0.31^{\star}$ & 0.00 & 0.00 & 0.00 & 0.00 \\
\hline F. fossana & $0.98 \pm 0.02^{*}$ & $0.98 \pm 0.02^{*}$ & 0.00 & 0.00 & 0.00 & 0.00 \\
\hline G. e. elegans & $1.00^{*}$ & $1.00^{*}$ & $0.77 \pm 0.10$ & $0.19 \pm 0.12$ & $0.77 \pm 0.10$ & $0.19 \pm 0.12$ \\
\hline G. fasciata & $0.57 \pm 0.13$ & $0.23 \pm 0.10$ & $0.67 \pm 0.09$ & $0.04 \pm 0.04$ & $0.67 \pm 0.09$ & $0.04 \pm 0.04$ \\
\hline Felis spp. & 0.00 & 0.00 & $0.64 \pm 0.12$ & $0.64 \pm 0.12$ & $0.41 \pm 0.09$ & $0.41 \pm 0.09$ \\
\hline$V$. indica & 0.00 & 0.00 & $0.57 \pm 0.08$ & $0.94 \pm 0.04$ & $0.57 \pm 0.08$ & $0.94 \pm 0.04$ \\
\hline
\end{tabular}

${ }^{*}$ Naïve occupancy (the raw proportion of camera stations that detected each species uncorrected for detection probability) is presented because of a limited dataset or because the naïve occupancy equals 1 or close to 1 at those grids, and thus modelling factors affecting detection probability and occupancy was not possible

both fragmented forests, and C. ferox only detected in the fragments $<2.5 \mathrm{~km}$ from intact forest. We observed exotic carnivores in all four rainforests. Of these species only the domestic dog Canis familiaris was detected in the primary and selectively-logged forests, whereas $C$. familiaris, wild and/or feral cats that co-occur and probably hybridize with Felis spp., and small Indian civet Viverricula indica were found in both fragmented forests.

Among all rainforests 423 trap nights or less were needed to achieve a $95 \%$ probability of a single detection of most carnivores. The two exceptions were E. goudotii in the primary forest $(1,081$ trap nights) and C. ferox in the fragments $<2.5 \mathrm{~km}$ (1,375 trap nights). Assuming capture frequencies were similar among forests where species were detected and not detected, our sampling effort at each forest was above the necessary trap nights to achieve a $95 \%$ probability of detecting all carnivores in each forest, except for C. ferox in the fragments $>15 \mathrm{~km}$ (Table 1).

Because of the lack of recaptures of adequate juvenile C. ferox we limited our analyses to adults only. We detected one C. ferox in the fragments $<2.5 \mathrm{~km}$ but could not conduct a density analysis with a single individual (Table 1 ). We found the detection probabilities of both $F$. fossana and C. ferox were affected by Sex and H (Appendix 1).

F. fossana density in the primary forest was more than double the density in the selectively-logged forest $(3.19 \pm \mathrm{SE}$ 0.55 and $1.38 \pm$ SE $0.22 \mathrm{~km}^{-2}$, respectively). C. ferox density was an order of magnitude lower than $F$. fossana in the primary and selectively-logged rainforests $(0.12 \pm$ SE 0.05 , $0.09 \pm$ SE 0.04 adults $\mathrm{km}^{-2}$, respectively) but not significantly different between these forests. In the fragmented forest $<2.5 \mathrm{~km}$ from intact forest we concluded only that C. ferox density may be $>0$ as one individual was detected at two camera stations in the largest rainforest fragment (192 ha) in that grid, or zero if the animal was a transient.
Our fully parameterized occupancy models fit the data $(\mathrm{P}>0.05)$ and thus we maintained a $\hat{c}$ of 1.o. We found that the detection probability and site-level occupancy of native and exotic carnivores were influenced by camera-, grid- and landscape-level variables (Appendix 2). G. fasciata's average grid occupancy was higher in the primary forest than in the selectively-logged forest because of greater tree basal area in the former (Appendix 3, Fig. 2, Table 3). In comparison, our data showed that G. fasciata site occupancy in the fragmented rainforests was determined by fragment size (Appendix 3, Table 3); fragments $>50$ ha had a probability of occupancy $>95 \%$ (Fig. 2). G. fasciata was never detected in the matrix outside the rainforest fragments. In the contiguous rainforests we found no statistically significant habitat predictors of $C$. ferox occupancy (Appendices $2 \& 3$ ). We could not model factors affecting occupancy for either F. fossana or G. e. elegans because of their high naïve occupancy (i.e. proportion of camera stations that detected each species was 1 or close to 1) in the contiguous rainforests (Table 3). However, in the fragmented forests we found G. e. elegans had higher site occupancy within the fragments compared to the matrix (ForestType) and was negatively affected by increasing success of trapping Felis spp. (Appendix 3, Table 3); success of only four captures of Felis spp. per 100 trap nights reduced G. e. elegans occupancy in the fragments from 90 to $31 \%$. C. familiaris site occupancy in the contiguous rainforests was negatively related to increasing distance to the closest village from camera stations (DistVillage; Appendices 2 \& 3).

We estimated a total population of 8,626 adult C. ferox across Madagascar, with 4,476 in 32 populations in rainforest and 4,150 in 38 populations in dry forest. Ninety-five percent of the total rainforest population was contained in two forest complexes immediately north of Lac Alaotra Biological Reserve. Dry forests were more fragmented and $95 \%$ of the total population of C. ferox 

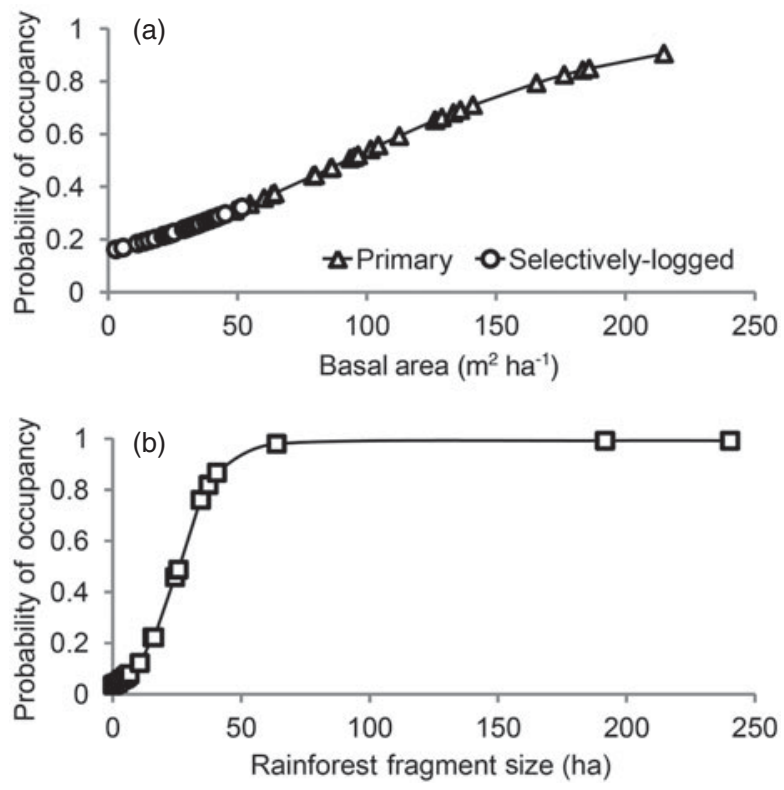

FIG. 2 Variation in the occupancy of broad-striped mongoose Galidictis fasciata with (a) tree basal area in contiguous rainforests in Ranomafana National Park and (b) fragment size in fragmented rainforests $(<2.5$ and $>15 \mathrm{~km}$ from intact contiguous rainforest), in Madagascar's eastern forests (Fig. 1) during May-October 2008 and October-December 2009, respectively.

was in nine populations and only two dry forest complexes could support $>300$ adults. Considering only protected forest we estimated an island-wide protected C. ferox population of 2,635 adults ( 780 in dry forest, 1,855 in rainforest). The protected areas of Masaola-Makira rainforest and Zahamena-Mantadia-Vohidrazana rainforest complex were the only areas identified as potentially holding $>300$ adult $C$. ferox.

\section{Discussion}

Within Madagascar's eastern rainforests logging, fragmentation and presence of exotic carnivores have significant negative implications for the conservation of native carnivores. Congruent with other studies of carnivore communities (Crooks, 2002; Michalski \& Peres, 2005) we found that forest fragmentation and the additive or synergistic effects associated with such disturbance altered the species composition of Malagasy carnivores such that contiguous rainforests held a higher number of native and a lower number of exotic carnivore species compared to fragmented rainforests. Among the rainforests we surveyed sensitivity to habitat disturbance differed by species, as in other studies (Crooks, 2002); the larger Euplerinae species (C. ferox, E. goudotii, F. fossana) were absent or nearly so from the fragmented rainforests, suggesting greater sensitivity compared to the smaller-bodied Galidiinae species (G. e. elegans, G. fasciata) that occupied fragmented forests.
Although we were 56 trap nights short of a $95 \%$ probability of detecting C. ferox in the fragments $>15 \mathrm{~km}$ from intact forest we are confident this species was absent, as a concurrent study found that no local people had observed C. ferox in recent years (2004-2009; Kotschwar, 2010).

The two native carnivores found to occupy fragmented rainforest were G. e. elegans and G. fasciata. However, G. fasciata was constrained to the larger fragments and G. e. elegans was negatively affected by increasing levels of activity by Felis spp.. The broad distribution of these exotic cats across Madagascar, their negative impact on G. e. elegans, and their documented predation upon diurnal lemurs (Brockman et al., 2008) make them a considerable threat to endemic mammals.

F. fossana appear to be particularly sensitive to forest disturbance. We found it absent from both fragmented rainforests; the species is also unlikely to occupy Madagascar's open, human-dominated landscapes (Kotschwar, 2010) and has been described as intolerant to degraded forests (Kerridge et al., 2003). Some evidence suggests $F$. fossana is able to use fragments $<2.5 \mathrm{~km}$ from intact forest, as they have been observed using fragments at $93-1,368 \mathrm{~m}$ from intact rainforest (Dehgan, 2003).

Selective-logging is known to have complex and often species-specific effects on mammals (Meijaard et al., 2005). Despite the selectively-logged forest we surveyed having reduced tree basal area and density and an altered canopy cover compared to the primary forest, we found no difference in the carnivore community composition between these areas. Either selective-logging prior to 1991 had not altered the carnivore composition, or contiguous unlogged forest facilitated recolonization in the last 2 decades.

Similar to findings for other top carnivores (e.g. Panthera tigris; Rayan \& Mohamad, 2009) the structurally-altered selectively-logged rainforest had a density of $C$. ferox similar to that of the primary forest. We hypothesize that the species' flexible diet may explain why it occupies diverse forests across Madagascar and is able to tolerate a certain level of forest disturbance. In agreement with previous findings that density of $C$. ferox in rainforest is lower than in dry forest (Gerber et al., 2010), the mean density of adults in rainforest $\left(0.105 \mathrm{~km}^{-2}\right)$ was also lower than that of adults in dry forest $\left(0.18 \mathrm{~km}^{-2}\right.$; Hawkins \& Racey, 2005). The lower density in rainforest may reflect a combination of more patchily distributed resources there, lower primate prey biomass compared to Madagascar's dry forests (Ganzhorn et al., 2003) or lower prey accessibility related to the more complex forest structure.

We found at least one exotic carnivore in each rainforest site, with $C$. familiaris being the most ubiquitous. In the contiguous rainforest use of the forests by $C$. familiaris was negatively related to the distance to the closest village, such that $>{ }_{4} \mathrm{~km}$ from a village C. familiaris is unlikely to use intact forest. Considering the many villages surrounding 
Ranomafana National Park we predicted that $15 \%$ of the Park has $>50 \%$ probability of use by C. familiaris. This is of concern as C. familiaris is expected to affect medium and small carnivores through interference competition and is known to be a disease vector (Vanak \& Gompper, 2009). In the dry forests C. familiaris and Felis spp. have been implicated in disease transmission to C. ferox (Dollar, 2006).

Although we recognize that our population model of C. ferox is imperfect because of our assumptions, and that forest cover is changing in Madagascar, conservation planners need data such as these upon which to begin discussions of management action. Our estimate of 2,635 adult C. ferox in protected areas is similar to Hawkins \& Racey's (2005) estimate of a total protected population of 2,500 adult $C$. ferox. We suggest that although a population estimate for protected areas may be overly conservative as a total population estimate, given that $C$. ferox occupies nonprotected contiguous forests (B.D. Gerber, pers. obs.), our population estimate for all forests may be overly liberal, given that poaching rates of $C$. ferox outside protected areas can be significant (Golden, 2009). We thus suggest that the island-wide population of $C$. ferox is somewhere between 2,635 and 8,626 adults.

There is a need to increase the size of protected areas across all forest types to maintain even moderate protected populations of $C$. ferox. This is especially true for dry forests; the largest protected dry forest area in our study is Kirindy Metea National Park ( $839 \mathrm{~km}^{2}$ of primary forest), with an estimated population of only 151 adult $C$. ferox. To protect C. ferox populations we suggest a focus on minimizing poaching by humans, and maintenance of forest structure and prey availability, rather than the exclusion of local people from forested areas. Additionally, establishing forested corridors between large fragments may encourage and maintain movements of potentially isolated carnivore populations, although improving connectivity comes with risks of disease transmission. Furthermore, as these carnivores are known to kill lemurs the potential effects of predator recolonization on threatened lemur populations must also be considered. If the benefits of reconnecting forest fragments are considered greater than the potential costs, two areas in the eastern rainforest should be a high priority for restoration: the gap between the two eastern rainforest complexes, which are only linked by a series of small $(<25 \mathrm{ha})$ fragments, and the area $16 \mathrm{~km}$ north of Ranomafana National Park, which has a gap of c. $4.5 \mathrm{~km}$ between forest fragments. Since this study was completed similar work has been underway in the Masoala-Makira rainforest region in north-eastern Madagascar (Z.J. Farris, pers. comm). Although the land management recommendations of our study have been communicated with both the Malagasy government and various NGOs, corridor restoration and large-scale land protection is on hold because of the current political uncertainty.

\section{Acknowledgements}

Funding provided by Virginia Tech, National Geographic Society Committee on Research and Exploration, Sigma Xi Virginia Tech Master's Degree and Grants-in-Aid Awards, National Science Foundation Graduate Research Fellowship Programme, and Burd Sheldon McGinnes Graduate Fellowship. We thank the Government of Madagascar, Madagascar National Parks, the Direction des Eaux et Forêts, and CAFF/CORE for permission to conduct this research. We were greatly assisted by ICTE/MICET, Centre ValBio, Ialatsara, Sadabe, and many remarkable research assistants. Design and analyses were greatly improved by the advice of D. Stauffer, M. Kelly, J. Cohen and J. Ivan.

\section{References}

Brockman, D., Godfrey, L., Dollar, L. \& Ratsirarson, J. (2008) Evidence of invasive Felis silvestris predation on Propithecus verreauxi at Beza Mahafaly Special Reserve, Madagascar. International Journal of Primatology, 29, 135-152.

Burnham, K.P. \& Anderson, D.R. (2002) Model Selection and Multimodel Inference: A Practical Information-Theoretic Approach. Springer-Verlag, New York, USA.

Carroll, C., Noss, R.F. \& Paquet, P.C. (2001) Carnivores as focal species for conservation planning in the Rocky Mountain region. Ecological Applications, 11, 961-980.

Conservation International (2010) Center for Applied Biodiversity Science. Http://www.learning.conservation.org/ spatial_monitoring/Forest/Pages/default.aspx [accessed 30 May 2011].

Crooks, K.R. (2002) Relative sensitivities of mammalian carnivores to habitat fragmentation. Conservation Biology, 16, 488-502.

Cumming, G. \& Finch, S. (2005) Inference by eye: confidence intervals and how to read pictures of data. American Psychologist, $60,170-180$.

Dehgan, A. (2003) The Behavior of Extinction: Predicting the Incidence and Local Extinction of Lemurs in Fragmented Habitats of Southeastern Madagascar. University of Chicago, Chicago, USA.

Dollar, L. (2006) Morphometrics, Diet, and Conservation of Cryptoprocta ferox. PhD thesis, Duke University, Durham, USA.

Dunnett, C.W. (1980) Pairwise multiple comparisons in the homogeneous variance, unequal sample size case. Journal of the American Statistical Association, 75, 789-795.

Durbin, J., Funk, S.M., Hawkins, F., Hills, D.M., Jenkins, P.D., Moncrieff, C.B. \& Ralainasolo, F.B. (2010) Investigations into the status of a new taxon of Salanoia (Mammalia: Carnivora: Eupleridae) from the marshes of Lac Alaotra, Madagascar. Systematics and Biodiversity, 8, 341-355.

EFFord, M.G. (2009) DENSITY 4.4: Software for Spatially Explicit Capture-Recapture. Http://www.otago.ac.nz/density [accessed 30 May 2011].

Efford, M.G., Borchers, D.L., Byrom, A.E. (2009) Density estimation by spatially explicit capture-recapture: likelihood-based methods. In Modeling demographic processes in marked populations (eds D.L. Thomson, E.G. Cooch \& M.J. Conroy), pp. 255-269. Springer, New York, USA.

Ganzhorn, J.U., Klaus, S., Ortmann, S. \& Schmid, J. (2003) Adaptations to seasonality: some primate and non-primate examples. In Primate Life Histories and Socioecology (eds P.M. 
Kappeler \& M.E. Pereira), pp. 132-148. University of Chicago Press, Chicago, USA.

Gerber, B. (2010) Comparing density analyses and carnivore ecology in Madagascar's southeastern rainforest. MS thesis, Virginia Polytechnic Institute and State University, Blacksburg, USA.

Gerber, B., Karpanty, S.M., Crawford, C., Kotschwar, M. \& Randrianantenaina, J. (2010) An assessment of carnivore relative abundance and density in the eastern rainforests of Madagascar using remotely-triggered camera traps. Oryx, 44, 219-222.

Gerber, B., Karpanty, S.M. \& Kelly, M.J. (2011) Evaluating the potential biases in carnivore capture-recapture studies associated with the use of lure and varying density estimation techniques using photographic-sampling data of the Malagasy civet. Population Ecology, 54, 43-54.

Golden, C.D. (2009) Bushmeat hunting and use in the Makira Forest, north-eastern Madagascar: a conservation and livelihoods issue. Oryx, 43, 386-392.

Goodman, S.M. (2003) Predation on lemurs. In The Natural History of Madagascar (eds S.M. Goodman \& J.P. Benstead), pp. 1221-1227. The University of Chicago Press, Chicago, USA.

Goodman, S.M. \& Helgen, K.M. (2010) Species limits and distribution of the Malagasy carnivoran genus Eupleres (Family Eupleridae). Mammalia, 74, 177-185.

Harper, G.J., Steininger, M.K., Tucker, C.J., Juhn, D. \& Hawkins, F. (2007) Fifty years of deforestation and forest fragmentation in Madagascar. Environmental Conservation, 34, 325-333.

HaW KINS, C.E. \& RaCey, P.A. (2005) Low population density of a tropical forest carnivore, Cryptoprocta ferox: implications for protected area management. Oryx, 39, 35-43.

Hines, J.E. (2006) Program PRESENCE. Http://www.mbr-pwrc.usgs. gov/software/presence.html [accessed 30 May 2011].

Irwin, M.T., Wright, P.C., Birkinshaw, C., Fisher, B.L., Gardner, C.J., Glos, J. et al. (2010) Patterns of species change in anthropogenically disturbed forests of Madagascar. Biological Conservation, 143, 2351-2362.

IUCN (2011) IUCN Red List of Threatened Species v. 2010.4. IUCN, Gland, Switzerland. Http://www.iucnredlist.org [accessed 30 May, 2011].

Karanth, K.U. \& Chellam, R. (2009) Carnivore conservation at the crossroads. Oryx, 43, 1-2.

Karanth, K.U. \& Nichols, J.D. (2002) Monitoring Tigers and Their Prey: A Manual for Researchers, Managers and Conservationists in Tropical Asia. Centre for Wildlife Studies, Bangalore, India.

Kerridge, F.J., Ralisoamalala, R.C., Goodman, S.M. \& Pasnick, S.D. (2003) Fossa fossana, Malagasy striped civet, Fanaloka. In Natural History of Madagascar (eds S.M. Goodman \& J.P. Benstead), pp. 1363-1365. The University of Chicago Press, Chicago, USA.

Kotschwar, M. (2010) Variation in predator communities and antipredator behaviors of lemurs in southeastern Madagascar. MS thesis, Virginia Polytechnic Institute and State University, Blacksburg, USA.

Kremen, C., Cameron, A., Moilanen, A., Phillips, S.J., Thomas, C.D., Beentje, H. et al. (2008) Aligning conservation priorities across taxa in Madagascar with high-resolution planning tools. Science, 320, 222-225.

Laurance, W.F. \& Cochrane, M.A. (2001) Special section: synergistic effects in fragmented landscapes. Conservation Biology, $15,1488-1489$.
MacKenzie, D.I. \& Bailey, L.L. (2004) Assessing the fit of site-occupancy models. Journal of Agricultural, Biological, and Environmental Statistics, 9, 300-318.

MacKenzie, D.I. \& Nichols, J.D. (2004) Occupancy as a surrogate for abundance estimation. Animal Biodiversity and Conservation, $27,461-467$.

McGarigal, K., Cushman, S.A., Neel, M.C. \& Ene, E. (2002) FRAGSTATS: Spatial Pattern Analysis Program for Categorical Maps. University of Massachusetts, Amherst, USA. Http://www. umass.edu/landeco/research/fragstats/fragstats.html [accessed 29 March 2012]

Meijaard, E., Sheil, D., Nasi, R., Augeri, D., Rosenbaum, B., IsKANDAR, D. et al. (2005) Life after Logging: Reconciling Wildlife Conservation and Production Forestry in Indonesian Borneo. CIFOR (Center for International Forestry Research), Bogor, Indonesia.

Michalski, F. \& Peres, C.A. (2005) Anthropogenic determinants of primate and carnivore local extinctions in a fragmented forest landscape of southern Amazonia. Biological Conservation, 124, 383-396.

Pollard, J.H. (1971) On distance estimators of density in randomly distributed forests. Biometrics, 27, 991-1002.

Rayan, D.M. \& Mohamad, S.W. (2009) The importance of selectively logged forests for tiger Panthera tigris conservation: a population density estimate in Peninsular Malaysia. Oryx, 43, $48-51$.

Roemer, G.W., Gompper, M.E. \& Valkengurgh, B.V. (2009) The ecological role of the mammalian mesocarnivore. Bioscience, 59, 165-173.

Tobler, M.W., Carrillo-Percastegui, S.E., Pitman, R.L., Mares, R. \& Powell, G. (2008) An evaluation of camera traps for inventorying large- and medium-sized terrestrial rainforest mammals. Animal Conservation, 11, 169-178.

Vanak, A.T. \& Gompper, M.E. (2009) Dogs Canis familiaris as carnivores: their role and function in intraguild competition. Mammal Review, 39, 265-283.

Yoder, A.D., Burns, M.M., Zehr, S., Delefosse, T., Veron, G., Goodman, S.M. \& FLYNN, J.J. (2003) Single origin of Malagasy Carnivora from an African ancestor. Nature, 421, 734-737.

Zar, J.H. (1998) Biostatistical Analysis. Prentice Hall, Upper Saddle River, USA.

\section{Appendices}

The Appendices for this article are available online at http:// journals.cambridge.org/orx

\section{Biographical sketches}

BRIAN D. GERBER's research has focused on carnivore and lemur ecology in Madagascar since 2007. He is currently studying the population ecology of the Sandhill crane and is interested in ecological modelling and estimation. SARAH KARPANTY has worked in Madagascar since 1997, focusing on predator-prey ecology across contiguous and fragmented rainforest landscapes. She continues to study predator-lemur interactions at multiple sites in eastern Madaagascar. JoHNY RANDRIANANTENAINA is a research assistant at Centre Valbio, where he specializes in camera trapping, vegetation sampling and surveys of primates. He is currently working as part of the Tropical Ecology Assessment and Monitoring Network in Ranomafana National Park. 